\title{
Somatic rhythmic motion effective on peristaltic circulation of cerebrospinal fluid: hypothesis for music- and sport-based interventions
}

\author{
Huibing Tan ${ }^{1}$, Torin Chiles ${ }^{1,2}$, Yinhua $\mathrm{Li}^{3,6}$, Tianyi Zhang ${ }^{3}$, Hangqi $\mathrm{Liu}^{4,5}$, Yunge $\mathrm{Jia}^{3,7}$, Wei Huo ${ }^{3}$, Xinghang \\ Wang ${ }^{3}$, Chenxu Rao ${ }^{3}$, Zichun Wen ${ }^{3}$, Ximeng Xu' ${ }^{3}$, Xiaoxin Wen ${ }^{3}$, Siyu Tian ${ }^{5}$
}

\begin{abstract}
${ }^{1}$ New St. James Presbyterian Church, London, Ontario, N6C 1J4, Canada; ${ }^{2}$ The Don Wright Faculty of Music, Western University, London, Ontario, N6A 3K7, Canada; ${ }^{3}$ Department of Anatomy, Jinzhou Medical University, Jinzhou, Liaoning, 121001, China. ${ }^{4}$ Harbin Conservatory of Music, Harbin, Heilongjiang, 150028, China, ${ }^{5}$ Art and Humanity College, Jinzhou Medical University, Jinzhou, Liaoning, 121001, ${ }^{6}$ China, School of Rehabilitation and Sports Medicine, Jinzhou Medical University, 121001, China, ${ }^{7}$ Department of Pathology, Heji Hospital Affiliated to Changzhi Medical College, Changzhi, Shanxi, 046011, China.
\end{abstract}

*Correspondence: Huibing Tan, E-mail: davidtanhb@foxmail.com

Cerebrospinal fluid (CSF)-contacting neurons (CSF-N) located in the surface of both brain ventricles and the central canal (cc) in the spinal cord. The cc and CSF maintain a proliferative niche for neural progenitor cells and play a vital role in development of the brain. The CSF circulates in the ventricles and the subarachnoid spaces with the CSF rhythmic flow: cardiac pulsation and respiratory fluctuation. A new concept of CSF motion may be contrary to the classical one that the direction of CSF motion may vary in direction and may be dynamic in its location. The CSF pressure may also depend on the body position. Moderate music-making has been considered a potential approach for rehabilitative and restorative therapy of brain dysfunctions. Recently, we find that the CSF-Ns are present in both the interior CFS in the $\mathrm{cc}$ and also exterior CSF around the surface of the spinal cord. We hypothesize that CSF-N as mechanical sensors in the spinal cord could sense motion of the spinal cord. The myodural bridge is a ligament connecting a pair of deep, upper-neck muscles to the dura mater, which envelops the arachnoid mater and contains the CSF surrounding the brain and the spinal cord. We figure out the term "CSF-static compartment" and classify CSF storage location as rostral pool and caudal pool to demonstrate our hypothesis. We presume that the somatic body movement with music-making and rehabilitation-based interventions would orchestrate the CSF motion with head movement, myodural bridge stretching and puling as well as spinal bending.

Key words : Music-making, Cerebrospinal fluid, Myodural bridge, Somatic rhythmic motion, CSF-static compartment

\section{Introduction}

Man a Machine (French: L'homme Machine) is a work of materialist philosophy in the 18th-century to demonstrate man is a machine based on straightforward mechanical condition [1]. Actually, human being is also a minding "machine" of biological functions deeply impacted with psychology. Consideration of man is a machine, the typical mechanical behaviors are human somatic movements. Physical therapy, music therapy, and rehabilitation-based intervention may be partially based on this reason. The most impressive on somatic rhythmic movement are corelated with musician with music-making. The other repetitive movements during dancing, 
sport and similar creating activities are also considered for our speculation. For neuroscience of music, most of research roadmaps are focused on cognitive processes underlying music or neuronal circuitry of perceiving sensation in the field of neuroscience and psychology[2-4]. Considering music therapy, physical therapy, sportor rehabilitation intervention, some approaches of the treatment rely on "mechanical movement" of nonpharmacology in physical medicine and rehabilitation $[5,6]$. Considering certain intensity of rhythmic and repetitive somatic movements applied during treatment, in the present article, we figure out conceptions of music bio-imagination and briefly discuss physical properties of somatic rhythmic movements impact on cerebrospinal fluid (CSF) based on relevant researches[7-10] and our research considerations[11-13].

\section{CSF pulsatility and circulation}

The CSF produced by the choroid plexus is occupied in the brain ventricles and the cranial and spinal subarachnoid spaces. The CSF coverage is meninges composed three layers: the dura mater, arachnoid mater and pia mater. The dura mater locates the exterior layer. The mean CSF volume is $150 \mathrm{ml}$, with $25 \mathrm{ml}$ in the ventricles and $125 \mathrm{ml}$ in subarachnoid spaces[14]. CSF-contacting neurons (CSF-N) are present in the surface of both brain ventricles and the central canal (cc) in the spinal cord $[15,16]$ as well as specific locations[17]. The CSF-Ns sense $\mathrm{pH}$ changes and motion in the hypothalamus[18]. Pioneer studies provide evidence in the circulation of the CSF[19]. Physiologically, deep sleep drives CSF rhythmic fluid flows. CSF pulsation can be observed both in the brain and spinal cord[20-22]. It is demonstrated as a cardiac-related CSF pulsation[20, 23, 24]. The normal respiration may also correlate with the brain stem motion[21, 25, 26]. Abnormal CSF pulsations may be used in the clinical application, for example assessment of spondylotic block [22]. Study and examination of brain pulsation make better understand brain function in health and with disease[27]. Interestingly, a new concept of CSF motion may be controversy to classical one that the direction of CSF motion may be various in directions and dynamics in where it locates [28]. Figure 1 showed CSF circulation in different patterns. The CSF pressure may also depend on the body position[26].

CSF contains biomolecules [29-31] or biomarkers[32, 33] and also metabolic products [34]. The circulation and drainage of CSF help keeping the brain and spinal health. Dalkilic et al suggest that compared with magnetic resonance imaging measures, the CSF biomarkers discriminate better between different injury severities for recovery after acute cervical spinal cord injury, and are stronger predictors of neurological recovery in terms of Association Impairment Scale grade and motor score improvement[35].

The CSF flow direction may not fit well with natural condition as we thought[19, 36, 37]. The body position and head or neck position play a role in spinal fluid flow[37]. An alternative CSF drainage should be used if normal CSF drainage was disordered[38]. In order to demonstrate relevant concept, we illustrate an outline for CSF circulation (figure 1). In this diagram, we introduce the myodural bridge which is suggested to correlate to CSF circulation (Figure 1 and Figure 2) [39].

\section{Myodural bridge}

CSF is preserved in skull and vertebral column. Martins et al create a concept: dural elasticity for "the spinal dura mater (together with the arachnoid mater) buttressed not by bone but by a network of veins and fat in the epidural space seems potentially able to alter its capacity"[40]. Meanwhile, the skull together with the cranial 
dura mater relatively, forms an unalterable rigid container for CSF.

There is a specialized ligament tissue, myodural bridge interiorly attached dura mater at the first cervical vertebra and the second vertebra, exteriorly connected with several neck muscle $[8,9]$. The myodural bridges connect a pair of upper-neck muscles, the rectus capitis posterior minor (RCPmi) rectus capitis posterior major (RCPma), and obliquus capitis inferior (OCI) suboccipital muscle, to the dura mater covering the spinal cord. The dura envelops the arachnoid mater in which contains the CSF surrounding the brain and the spinal cord[41]. Myodural bridge cross the cervical epidural space connects suboccipital muscle fascia and dura. Dura mater is innervated with neuronal network. Stimulation of cranial dura mater causes neurotransmitter release into the CSF and acts on the brain function[42]. We think that the myodural bridge can stretch spinal cord and acts on nervous system both biological and physically when our should and head move. Such, myodural bridges not only provides passive and active anchoring of the spinal cord, but also maintain patency of the CSF circulation by stretching or pulling dura in spinal cord as Xu et al demonstrate[39].

Our hypothesis is that the rhythmic body movement and head motion with music performing may physically act on the CSF. The cervical myodural bridge[43] connected dura mater of spinal cord may affect the CSF flow through some dorsal neck muscles[8].

\section{CSF circulation based on somatic movement}

Chiro demonstrates "At least a part of the lumbo-sacral CSF ascends to the basal cisterns. This upward movement takes place in about 1 hour, possibly faster in children."[19] First of all, we would like to classify spaces for CSF occupation in to CSF rostral (head) pool and CSF caudal pool. The CSF rostral pool abbreviated rostral pool, includes ventricles, subarachnoid spaces and cisterns (for example cerebellomedullaris cistern or cisterna magna) inside the skull. The CSF caudal pool abbreviated rostral pool locates in the caudal end of the conus medullaris, especially in adult human. The caudal pool is a specialized anatomy structure for lumber puncture. CSF pressure is a physical CSF occurrence in the subarachnoid spaces in vertebral column. It should be considered as a cistern or cistern-like space because caudal part of the caudal pool is confined in the sacral canal of the sacrum which is a dead-end segment. To our knowledge, we do not find a specialized anatomy term to definite the location. Chiro mentions the anatomy position as the lumbo-sacral "cul de sac"[19]. And Rieselbach et al name the position as lumbar sac[36]. The caudal pool is a very important and widely known for investigation and clinical diagnosis. Lumber puncture at the caudal pool can provide a measurement of cranial pressure. Normal pressure measured by lumber puncture is 6 to $25 \mathrm{cmH}_{2} \mathrm{O}$ (95\% confidence intervals)[44]. It takes 45min injection of radioactive drug to reach cisterna magnus in Trenderlenburg position in monkey experimental model[36]. Dyes injected into the lateral ventricles make their appearance in the cisterna magna within a few minutes and may be detected in the lumbar fluid after 40 minutes (see review) [19]. CSF is supposed to move upward motion. Through lumbar puncture, the injection of radioactive tracer can finally reach the endocranium, while strong activity can remain for 48 hours[19]. Withdrawal and re-injection drug could not improve subarachnoid distribution of drugs compared to similar volume of one lumbar injection[36]. Such, we suggested that the rostral pool and caudal pool are relative separated spaces regard to regular fluid mechanics. We think that rhythmic motion of head and vertebral column physically provided train of peristaltic waves or pumping driven to act on the CSF circulation and drainage (Figure 3). Lever drum pump also named hand pump is manually operated pump. By using human power and mechanical devices, fluids or air can be moved from 
one place to another. We try to illustrate and imagine force rod as spinous process according to Figure $3 \mathrm{~B}$. The spinous processes in sagittal plane of spinal cord are arranged tandem force rods to operate "pumps" (Figure 3B). It causes CSF fluctuation or peristaltic motion when back muscles contraction and spine bending.

The lever drum pump is not completely an analogy to spinous process or vertebral column, which composed with its joints, ligaments, discs and spinal cord as well as meninges, especially referred to caudal cervical, thoracic and lumber segments. The mechanism is not the same but the shape of lever drum pump helps us biometrically imaging spinous process as force rod pumping. Such, lever drum pump let us think about somatic movement which works as biological mechanical force acting on CSF.

Otherwise, compared to blood circulation and lymphatic drainage, CSF is confined in the skull and vertebral column which composed with its joints, ligaments, discs and spinal cord as well as meninges. It is a relative fluid static condition, although CSF constantly circulates and drainages. We term the configurate structure and space occupied by fluid as CSF-static compartment. The consideration is based on united CSF and surrounding structures into a combined structural and functional entity. CSF spatial distribution around the spinal cord presents a segmental chain pattern[45]. It is not an isolated circulation system. Vertebral column lymphatic vessels drain the dura mater around the spinal cord as well $[45,46]$. Furthermore, we presume that somatic movements would facilitate lymphatic drainage.

\section{CSF-static-dynamics and concepts on bio-fluid mechanics}

The CSF maintains a proliferative niche for neural progenitor cells[47]. Figure 4 shows ependymal cell zone, a typical model of latent stem cell niche around the $\mathrm{cc}$ in the spinal cord $[15,16]$. The CSF plays a vital role in development of the brain[48]. Neuromodulation via the CSF strongly influence neuronal activity [49]. Recently, we find that the CSF-Ns are present in both the interior CFS, the wall of $\mathrm{cc}$ and also exterior CSF, the surface or subpial of the spinal cord[11, 12]. We also hypothesis that CSF-N in the spinal cord may sense motion of the spinal cord[11] ( Figure 4 and Figure 5. There is a special fiber in the middle of the cc, Reissner's fiber, which play important role in to detecting spinal curvature [50]. Reissner fiber to CSF-cNs pathway makes a critical development guiding body axis morphogenesis [51, 52]. Reissner fiber is non-cellular strucute and composed of glycoproteins that are secreted into CSF from the subcommissural organ[53]. Reissner fiber should mechanically act on CSF-N. Additionally, we mention an analogy of the avian lumbosacral organ $[54,55]$ to similarity of Reissner fiber, because the avian lumbosacral specializations $[13,56]$ of the vertebral canal may be referred as a possible function as a sense organ of equilibrium [56, 57].

The human fluid-filled cc extends throughout the spinal cord[58]. We category CSF into interior CSF in the cc and exterior CSF surround surface of the spinal cord[11]. By using NADPH diaphorase staining, we found some NADPH diaphorase neurons distribute in the lateral funiculus of thoracolumbar spinal cord in monkey. The dendritic arbor can reach both interior CSF and exterior CSF[11] (Figure 5). The spinal cord bending or spine curvature could be detected by funicular neurons in the funicular plexus and subpial plexus (Figure 6). The location of in the funicular plexus and subpial plexus reminds us intraspinal stretch receptor neurons in lamprey for the neurons mediate different motor responses along the body[59]. The funicular plexus and subpial plexus in the spinal cord of monkey are considered an analogue to intraspinal stretch receptor neurons in lamprey. It is a speculation that intraspinal sensory neuron may also exit in the monkey spinal cord. In the sensory system, 
most of the perikaryons of sensory neurons locate peripherally central nervous system in mammary animals. We further deduce that these intraspinal neurons of monkey could perceive pressure from CSF and spinal cord bending. In the caudal spinal cord, we also find that NADPH diaphorase positive pathway links between the cc and the anterior median fissure (Figure 7). Stenosis or occlusion of the cc occurs in $70 \%$ to $80 \%$ of normal adults[60]. Occlusion could happen with aging, which may interfere the interior CSF circulation.

Stoodley et al set a model that arterial pulsation-dependent perivascular CSF flow into the cc in the spinal cord[61]. Bi demonstrates three model categories for fluid flows[62]. CSF flow presents CSF-static-dynamics. The distinguished characteristic of fluids compared with solids is related to the amount of deformation rate. Fluids show a continuous deformation when they get exposed to a shear force[63]. As liquids at rest and in motion in natural condition, CSF-static system shows a structural and functional adaptation in biological behavior. CSF is liquid/fluid mechanic fundamental concepts. Myodural bridge and spine bending acting on CSF are not constrained by a static dispositional machinery, but it should be considered as dynamical systems response to music-making.

Music-making associated physical force could percept through CSF. Liquid transform force must be different from hearing sounding or vision sensation. Throughout vertebrates, CSF-Ns locate among the ependymal zone surrounding the $\mathrm{cc}$ in the spinal cord according general studies[64, 65]. While, some neuronal somas of CSF-Ns are considered in parenchymal positions not close to cc or ventricle lumens[66, 67]. Most interesting to present hypothesis, CSF-Ns can regulate locomotion with mechanical stimulation in spinal cord[68].

Again, we reviewed spinal cord position, curvature or bending and CSF circulation. Together with specialized structure in the spinal cord of bird or pigeon[13], we discuss conceptions of music bio-imagination, experimental and observational support and CSF-N motion detection and control.

\section{Hypothesis for somatic movement relevant with music-making}

Many physical therapy and rehabilitation are music based physical rehabilitation [6]. We believe that professional musicians and amateur musicians make music benefit from rhythmic somatic movement duirng music-making.

As a prevailing leisure and professional activity, moderate music-making has effect on brain and cognitive development and has been considered a potential approach for rehabilitative and restorative therapy of brain dysfunctions[69]. Brain structural adaptations are clearly found among professional musicians, amateur musicians and/ or non-musicians [70-73]. However, it still lacks the study if somatic motions during the musicmaking could affect CSF movement or circulation. CSF pulsation is related the heartbeat. We presume that body motion definitely should affect on CSF. Playing a musical instrument comes with a mechanical action and will benefit circulation CSF?

We postulated that the music-initiated body motion generates a "programed" CSF motion. Besides traditional ways of music improvement of brain function and structure, the somatic body movement during the musicmaking would orchestrate the CSF motion with head movement, myodural bridge stretching and spinal bending etc. 


\section{Beneficial effect}

The investigation of Influence of sitting postures on neck and shoulder EMG. during arm-hand work movements [74] strongly prompt that music-making or performing with hand-arm-shoulder muscular activity and body posture form composite somatic movements. In this study, they have demonstrated the arm/hand is significantly influenced by the sitting postures chosen. Interestingly, the location of EMG recording electrodes distributes covering or around myodural bridge according to the Figure 1-3 in Schüldt's paper (see paper for elaboration)[74]. We note that marked activity changes are obtained while changing posture with spine[74, 75]. Such, we illustrate Figure 8 to engage experiments of neck-shoulder EMG with music-making which fingerhand-arm-shoulder-neck-head entity with spine-position. Of course, the legs should importantly entity with music while playing piano, organ and performing in marching band. These experimental results suggest that hands and arms of instrument players impact on the muscular activities of the neck and shoulders. Undeniably, musicians' movement synchrony is co-contraction and coordinate with the head and spine movements, even full body movements during music making. Overall, the muscular actions simultaneously form reaction of myodural bridge.

We emphasize that rhythmic and repetitive somatic movements make beneficial effect on CSF circulation. Most striking impairments of the somatic rhythmic and repetitive movements is considered in clinical manifestations correlate to most common neurodegenerative disease: Parkinson's disease[76]. Assessment of Parkinson disease, Tavares et al design kinematics of a repetitive alternating finger-tapping task[77], which rely on a computerinterfaced musical keyboard. We believe that the design of musical keyboard interface is an advance idea to compromises the progression of disease. Conceptions of music bio-imagination and music preservation in recognition may serve as a promising avenue to enhanced quality of life for a group of people who have lost so many other abilities. Hand rehabilitation often consists of repetitive exercises, which may result in reduced patient compliance and decreased results. Music based rehabilitation device [78] could be used as an engaging form of hand rehabilitation. Frontier tech featured haptic music instruction system could be applied to hand rehabilitation for patients of spinal cord injury [79]. Music therapy is a combination of specific muscle activating performance. The approach of music therapy or intervention sometimes is to trigger and help control body movements. Our speculations also could partially get verification with other investigations [80-82]. Besides instrument performance, featured repetitive movements, dance movement therapy integrates the use of music with movement therapy for patients of spinal cord injuries[83]. Synchronized head movement is expected an important contributor to human CSF circulation[7].

Classical Musicians for its creative profession correlate with relative longer life expectancy than that of average lifespan of general population and longevity [84, 85]. Many outstanding musicians and academic musicians keep longer professional lifespan[86]. Lifespan and Longevity are relatively classical musicians such as conductor, pianist, violinist. Of course, we think that conductor or violin player could make an alteration on the basic model. We notice a denotation in website of Western University in Canada: Conductors flap their arms around for many hours a day. Upper body exercises are a great cardio-vascular workout because they expand the muscles of the chest and open the lungs. Plus, the movements cause your heart to pump strongly, so blood and nutrients flow to your muscles and organs. (https://ir.lib.uwo.ca/westernpublichealthcases/vol2016/iss1/17/). Even, marching band can be also considered a combination of music and sport. However, Speechley believes that some cases are 
not truth for choosing appropriate controls considering aspects of epidemiology[84].

As mentioned above, upper body movements definitely commix with head and neck movements during conducting an orchestra performing. Strengthening multisensory and motor integration as well as improving brain plasticity, music learning and repeatedly practice and music-making is beneficial engagement for musicians with lifetime[87]. Investigation of Finnish performing artists and church musicians evaluating with the standardized mortality ratios, Kuusi et al suggest a protective effect of music for health [88]. In this investigation, performing artists are not protected from neurodegenerative diseases or alcohol-related deaths[88]. Interestingly, Cowles et al report a moderately demented patient of 80-year old with probable Alzheimer's disease who learned to play a song on the violin that was published after the apparent onset of his dementia (See paper for elaboration) [89]. Another case report shows that a pianist of a family history of Alzheimer disease preserves episodic musical memory after 5 years diagnosis[90]. These stories shed light on protection of musicians from neurodegenerative diseases and or even mental illness.

The professional musicians confront challenges. A case study of one orchestra in the US shows that workgenerated stress has effect on the members of the orchestra[91]. We believe that most of classical musicians are trained to pursuit perfect meaningful work and accomplishment. Many musicians are expected for solo playing, while, orchestral position is often regarded as a sort of disappointment in a certain extend (see review) [92]. The popular musician lifestyle is problematic social and psychology. Contrast to classical musicians, "that popular musicians have shortened life expectancy compared with comparable general populations" and "showed excess mortality from violent deaths (suicide, homicide, accidental death, including vehicular deaths and drug overdoses) and liver disease for each age group studied compared with population mortality patterns "[93].

\section{Conclusion}

Human organized with many machinery or physical mechanisms, music experiencing unites somatic movement and mind coordination, brain activities voluntarily scales to higher excitatory. There is a structure, myodural bridge, which connects to dura mater of spinal cord in the neck. And intraspinal sensory neurons and its network detect relevant mechanosensory modulation and biochemical alteration. Regarding music and "empathy" in CSF, flow state from music to dance, sport and or athletes [94], the CSF movements may be also considered as essential rehabilitation for neuronal injury if experiments could prove our hypothesis in future study. Significantly positive impact, music making becomes a tool for nourishing brain and soul across the life span[87]. We can design a special program based on the concept of the beneficial effects of the CSF circulation to improve with the somatic body movement combined during music-making. It is conceptions of music bio-imagination linked to music biomechanics, music psychology and psychiatry as well as philosophy (Figure 9). We figure out a postulation that somatic rhythmic movements during music making form somatic movements-CSFneurocircuitry-function adaptation ensemble. In this review, we emphasize our ideas based on the rhythmic movement effect of music-making on the CSF movement and perception-neuroplasticity as well as function adaptation (Figure 10). The way of music-making is the way of keeping body in motion that directly or indirectly impacts CSF circulation.

In summary, we postulated that the somatic body movement during music-making would orchestrate the CSF motion with head movement, myodural bridge stretching and spinal bending etc. The proposed study assumes that all rhythmic movements made in concert with classical music (movements made making music, dancing, 
and even repetitive movements made while listening to music) share the same beneficial effects of CSF circulation

Acknowledgement: The main idea about this paper is taken from our poster in 16th Annual NeuroMusic Conference "Music in Cross-Cultural Perspective" (November 14th, 2020, DOI: 10.13140/RG.2.2.23811.12323). Figure 1 cited with permission from J Can Chiropr Assoc. 2014 Jun;58(2):184-92 (Original anatomical artwork by Frank Scali, D.C., and Danny Quirk. Clin Anat. 2013 May; 26(4):444-9)[9]. Figure 2 cited from Chin J Neurotrauma Surg (Electronic Edition), 2015, Vol.1, No.3, DOI: 10.3877/cma.j.issn.2095-9141.2015.03.013), with permission originally adopted from Hugnot JP, Franzen R. Front Biosci (Landmark Ed), 2011, 16: 1044$1059[10]$.

\section{The authors declare no conflict of interest}

\section{Reference:}

[1] J.J.O. La Mettrie, J.O. de La Mettrie, La Mettrie: Machine Man and Other Writings, Cambridge University Press1996.

[2] M. Trimble, D. Hesdorffer, Music and the brain: the neuroscience of music and musical appreciation, BJPsych Int, 14 (2017) 28-31.

[3] M.H. Thaut, M. Thaut, Rhythm, music, and the brain: Scientific foundations and clinical applications, Routledge2005.

[4] I. Peretz, R. Zatore, The biological foundations of music, Language, brain, and cognitive development: Essays in honor of Jacques Mehler, DOI (2001) 435-443.

[5] S. Paul, D. Ramsey, Music therapy in physical medicine and rehabilitation, Australian Occupational Therapy Journal, 47 (2000) 111-118.

[6] C.M. Weller, F.A. Baker, The role of music therapy in physical rehabilitation: a systematic literature review, Nordic Journal of Music Therapy, 20 (2011) 43-61.

[7] Q. Xu, S.B. Yu, N. Zheng, X.Y. Yuan, Y.Y. Chi, C. Liu, X.M. Wang, X.T. Lin, H.J. Sui, Head movement, an important contributor to human cerebrospinal fluid circulation, Scientific reports, 6 (2016) 31787.

[8] D.E. Enix, F. Scali, M.E. Pontell, The cervical myodural bridge, a review of literature and clinical implications, J Can Chiropr Assoc, 58 (2014) 184-192.

[9] F. Scali, M.E. Pontell, A.B. Welk, T.K. Malmstrom, E. Marshall, N.W. Kettner, Magnetic resonance imaging investigation of the atlanto - axial interspace, Clinical anatomy, 26 (2013) 444-449.

[10] J.P. Hugnot, R. Franzen, The spinal cord ependymal region: a stem cell niche in the caudal central nervous system, Front Biosci, 16 (2011) 1044-1059.

[11] Y. Li, W. Hou, Y. Jia, X. Wen, C. Rao, X. Xu, Z. Wei, L. Bai, H. Tan, Pial surface CSF-contacting texture, subpial and funicular plexus in the thoracic spinal cord in monkey: NADPH diaphorase histological configuration, bioRxiv, DOI 10.1101/2020.01.30.927509(2020) 2020.2001.2030.927509.

[12] Y. Jia, Y. Li, W. Hou, F. Li, H. Sun, X. Wu, X. Wen, Z. Wei, C. Rao, X. Xu, A pathway of NADPH diaphorase positivity between central canal and pial surface at anterior fissure in spinal cord: Supra fissure area with hypothesis configuring from dog, rat, monkey and pigeon, bioRxiv, DOI (2020).

[13] Y. Jia, W. Hou, Y. Li, X. Wen, C. Rao, Z. Wei, T. Zhang, X. Wang, X. Li, L. bai, W. Zhang, P. Wang, J. Bi, A. Guo, J. 
Wang, H. Tan, A comparative assessment of aging-related NADPH diaphorase positivity in the spinal cord and medullary oblongata between pigeon and murine, bioRxiv, DOI 10.1101/650457(2019) 650457.

[14] L. Sakka, G. Coll, J. Chazal, Anatomy and physiology of cerebrospinal fluid, European annals of otorhinolaryngology, head and neck diseases, 128 (2011) 309-316.

[15] 魏子淳, 王宇, 徐熙萌, 吴畏, 饶晨旭, 谭会兵, 脊髓室管膜细胞再生修复的潜力和其他相关细胞靶向治 疗策略，中华神经创伤外科电子杂志，1 (2015) 50-54.

[16] J.P. Hugnot, R. Franzen, The spinal cord ependymal region: a stem cell niche in the caudal central nervous system, Front Biosci (Landmark Ed), 16 (2011) 1044-1059.

[17] S.-Y. Song, Y. Li, X.-M. Zhai, Y.-H. Li, C.-Y. Bao, C.-J. Shan, J. Hong, J.-L. Cao, L.-C. Zhang, Monosynaptic Input Mapping of Diencephalic Projections to the Cerebrospinal Fluid-Contacting Nucleus in the Rat, Frontiers in Neuroanatomy, 14 (2020) 7.

[18] E. Jalalvand, B. Robertson, H. Tostivint, P. Löw, P. Wallén, S. Grillner, Cerebrospinal fluid-contacting neurons sense $\mathrm{pH}$ changes and motion in the hypothalamus, Journal of Neuroscience, 38 (2018) 7713-7724.

[19] G. Di Chiro, Observations on the circulation of the cerebrospinal fluid, Acta Radiologica. Diagnosis, 5 (1966) 9881002.

[20] G. Schroth, U. Klose, Cerebrospinal fluid flow, Neuroradiology, 35 (1992) 1-9.

[21] S.E. Maier, C.J. Hardy, F.A. Jolesz, Brain and cerebrospinal fluid motion: real-time quantification with M-mode MR imaging, Radiology, 193 (1994) 477-483.

[22] B. Lane, I.I. Kricheff, Cerebrospinal Fluid Pulsations at Myelography: A Videodensitometric Study, Radiology, 110 (1974) 579-587.

[23] M. Klarica, M. Radoš, D. Orešković, The Movement of Cerebrospinal Fluid and Its Relationship with Substances Behavior in Cerebrospinal and Interstitial Fluid, Neuroscience, 414 (2019) 28-48.

[24] R. Adolph, H. Fukusumi, N. Fowler, Origin of cerebrospinal fluid pulsations, American Journal of PhysiologyLegacy Content, 212 (1967) 840-846.

[25] G. Du Boulay, J. O'connell, J. Currie, T. Bostick, P. Verity, Further investigations on pulsatile movements in the cerebrospinal fluid pathways, Acta Radiologica. Diagnosis, 13 (1972) 496-523.

[26] L. Chen, A. Beckett, A. Verma, D.A. Feinberg, Dynamics of respiratory and cardiac CSF motion revealed with realtime simultaneous multi-slice EPI velocity phase contrast imaging, Neuroimage, 122 (2015) 281-287.

[27] M.E. Wagshul, P.K. Eide, J.R. Madsen, The pulsating brain: A review of experimental and clinical studies of intracranial pulsatility, Fluids and Barriers of the CNS, 8 (2011) 5.

[28] M. Matsumae, K. Kuroda, S. Yatsushiro, A. Hirayama, N. Hayashi, K. Takizawa, H. Atsumi, T. Sorimachi, Changing the Currently Held Concept of Cerebrospinal Fluid Dynamics Based on Shared Findings of Cerebrospinal Fluid Motion in the Cranial Cavity Using Various Types of Magnetic Resonance Imaging Techniques, Neurologia medico-chirurgica, 59 (2019) 133-146.

[29] S. Ishiwata, K. Hattori, S. Hidese, D. Sasayama, T. Miyakawa, R. Matsumura, Y. Yokota, S. Yoshida, H. Kunugi, Lower cerebrospinal fluid CRH concentration in chronic schizophrenia with negative symptoms, Journal of Psychiatric Research, DOI (2020).

[30] J. Royds, M.J. Conroy, M.R. Dunne, H. Cassidy, D. Matallanas, J. Lysaght, C. McCrory, Examination and characterisation of burst spinal cord stimulation on cerebrospinal fluid cellular and protein constituents in patient responders with chronic neuropathic pain-A Pilot Study, Journal of Neuroimmunology, DOI (2020) 577249.

[31] E.C.B. Johnson, E.B. Dammer, D.M. Duong, L. Ping, M. Zhou, L. Yin, L.A. Higginbotham, A. Guajardo, B. White, J.C. Troncoso, M. Thambisetty, T.J. Montine, E.B. Lee, J.Q. Trojanowski, T.G. Beach, E.M. Reiman, V. Haroutunian, M. Wang, E. Schadt, B. Zhang, D.W. Dickson, N. Ertekin-Taner, T.E. Golde, V.A. Petyuk, P.L. De Jager, D.A. Bennett, T.S. Wingo, S. Rangaraju, I. Hajjar, J.M. Shulman, J.J. Lah, A.I. Levey, N.T. Seyfried, Large-scale proteomic analysis of Alzheimer's 
disease brain and cerebrospinal fluid reveals early changes in energy metabolism associated with microglia and astrocyte activation, Nature medicine, 26 (2020) 769-780.

[32] E.C. Johnson, E.B. Dammer, D.M. Duong, L. Ping, M. Zhou, L. Yin, L.A. Higginbotham, A. Guajardo, B. White, J.C. Troncoso, Large-scale proteomic analysis of Alzheimer's disease brain and cerebrospinal fluid reveals early changes in energy metabolism associated with microglia and astrocyte activation, Nature medicine, 26 (2020) 769-780.

[33] C. d'Abramo, L. D'Adamio, L. Giliberto, Significance of Blood and Cerebrospinal Fluid Biomarkers for Alzheimer's Disease: Sensitivity, Specificity and Potential for Clinical Use, Journal of Personalized Medicine, 10 (2020) 116.

[34] G. Klinke, S. Richter, P. Monostori, B. Schmidt-Mader, A. García-Cazorla, R. Artuch, S. Christ, T. Opladen, G.F. Hoffmann, N. Blau, J.G. Okun, Targeted cerebrospinal fluid analysis for inborn errors of metabolism on an LC-MS/MS analysis platform, Journal of Inherited Metabolic Disease, 43 (2020) 712-725.

[35] T. Dalkilic, N. Fallah, V.K. Noonan, S. Salimi Elizei, K. Dong, L. Belanger, L. Ritchie, A. Tsang, E. Bourassa-Moreau, M.K. Heran, Predicting injury severity and neurological recovery after acute cervical spinal cord injury: a comparison of cerebrospinal fluid and magnetic resonance imaging biomarkers, Journal of Neurotrauma, 35 (2018) 435-445.

[36] R.E. Rieselbach, G.D. Chiro, E.J. Freireich, D.P. Rall, Subarachnoid distribution of drugs after lumbar injection, New England Journal of Medicine, 267 (1962) 1273-1278.

[37] B. Funkquist, Cervical Myelography with a Water-Soluble Contrast Medium an Experimental Study in Dogs, Acta Radiologica, DOI (1961) 257-274.

[38] H.I. Farhat, M.S. Elhammady, A.D. Levi, M.A. Aziz-Sultan, Cervical Subarachnoid Catheter Placement for Continuous Cerebrospinal Fluid Drainage: A Safe and Efficacious Alternative to the Classic Lumbar Cistern Drain, Operative Neurosurgery, 68 (2011) ons52-ons56.

[39] Q. Xu, S.-B. Yu, N. Zheng, X.-Y. Yuan, Y.-Y. Chi, C. Liu, X.-M. Wang, X.-T. Lin, H.-J. Sui, Head movement, an important contributor to human cerebrospinal fluid circulation, Scientific reports, 6 (2016) 31787.

[40] A.N. Martins, J.K. Wiley, P.W. Myers, Dynamics of the cerebrospinal fluid and the spinal dura mater, Journal of neurology, neurosurgery, and psychiatry, 35 (1972) 468-473.

[41] B. Bordoni, M. Simonelli, M.M. Lagana, Tentorium cerebelli: muscles, ligaments, and dura mater, part 1, Cureus, 11 (2019).

[42] M. Dux, C. Will, M. Eberhardt, M.J. Fischer, K. Messlinger, Stimulation of rat cranial dura mater with potassium chloride causes CGRP release into the cerebrospinal fluid and increases medullary blood flow, Neuropeptides, 64 (2017) 61-68.

[43] G.D. Hack, R.T. Koritzer, W.L. Robinson, R.C. Hallgren, P.E. Greenman, Anatomic relation between the rectus capitis posterior minor muscle and the dura mater, Spine, 20 (1995) 2484-2486.

[44] S.C. Lee, C.J. Lueck, Cerebrospinal fluid pressure in adults, J Neuroophthalmol, 34 (2014) 278-283.

[45] L. Jacob, L.S.B. Boisserand, L.H.M. Geraldo, J. de Brito Neto, T. Mathivet, S. Antila, B. Barka, Y. Xu, J.-M. Thomas, J. Pestel, Anatomy and function of the vertebral column lymphatic network in mice, Nature communications, 10 (2019) 1-16.

[46] R.S. Dave, P. Jain, S.N. Byrareddy, Functional meningeal lymphatics and cerebrospinal fluid outflow, Journal of Neuroimmune Pharmacology, 13 (2018) 123-125.

[47] Maria K. Lehtinen, Mauro W. Zappaterra, X. Chen, Yawei J. Yang, A.D. Hill, M. Lun, T. Maynard, D. Gonzalez, S. Kim, P. Ye, A.J. D'Ercole, Eric T. Wong, Anthony S. LaMantia, Christopher A. Walsh, The Cerebrospinal Fluid Provides a Proliferative Niche for Neural Progenitor Cells, Neuron, 69 (2011) 893-905.

[48] J.A. Miyan, M. Nabiyouni, M. Zendah, Development of the brain: a vital role for cerebrospinal fluid, Canadian journal of physiology and pharmacology, 81 (2003) 317-328.

[49] A. Bjorefeldt, S. Illes, H. Zetterberg, E. Hanse, Neuromodulation via the Cerebrospinal Fluid: Insights from Recent in Vitro Studies, Frontiers in Neural Circuits, 12 (2018). 
[50] A. Orts-Del'Immagine, Y. Cantaut-Belarif, O. Thouvenin, J. Roussel, A. Baskaran, D. Langui, F. Koëth, P. Bivas, F.-X. Lejeune, P.-L. Bardet, Sensory Neurons Contacting the Cerebrospinal Fluid Require the Reissner Fiber to Detect Spinal Curvature In Vivo, Current Biology, 30 (2020) 827-839. e824.

[51] Y. Cantaut-Belarif, A. Orts Del'Immagine, M. Penru, G. Pézeron, C. Wyart, P.-L. Bardet, Adrenergic activation modulates the signal from the Reissner fiber to cerebrospinal fluid-contacting neurons during development, eLife, 9 (2020) e59469.

[52] Y. Cantaut-Belarif, J.R. Sternberg, O. Thouvenin, C. Wyart, P.L. Bardet, The Reissner Fiber in the Cerebrospinal Fluid Controls Morphogenesis of the Body Axis, Current biology : CB, 28 (2018) 2479-2486.e2474.

[53] R.I. Muñoz, T. Kähne, H. Herrera, S. Rodríguez, M.M. Guerra, K. Vío, R. Hennig, E. Rapp, E. Rodríguez, The subcommissural organ and the Reissner fiber: old friends revisited, Cell and Tissue Research, 375 (2019) 507-529.

[54] K.E. Stanchak, C. French, D.J. Perkel, B.W. Brunton, The balance hypothesis for the avian lumbosacral organ and an exploration of its morphological variation, Integrative Organismal Biology, DOI 10.1093/iob/obaa024(2020).

[55] K.E. Stanchak, C. French, D.J. Perkel, B.W. Brunton, The balance hypothesis for the avian lumbosacral organ and an exploration of its morphological variation, bioRxiv, DOI 10.1101/2020.04.01.020982(2020) 2020.2004.2001.020982.

[56] R. Necker, The structure and development of avian lumbosacral specializations of the vertebral canal and the spinal cord with special reference to a possible function as a sense organ of equilibrium, Anat Embryol (Berl), 210 (2005) 59-74.

[57] R. Necker, Specializations in the lumbosacral vertebral canal and spinal cord of birds: evidence of a function as a sense organ which is involved in the control of walking, Journal of Comparative Physiology A, 192 (2006) 439.

[58] E. Saker, B.M. Henry, K.A. Tomaszewski, M. Loukas, J. Iwanaga, R.J. Oskouian, R.S. Tubbs, The Human Central Canal of the Spinal Cord: A Comprehensive Review of its Anatomy, Embryology, Molecular Development, Variants, and Pathology, Cureus, 8 (2016) e927-e927.

[59] L.J. Hsu, P.V. Zelenin, S. Grillner, G.N. Orlovsky, T.G. Deliagina, Intraspinal stretch receptor neurons mediate different motor responses along the body in lamprey, The Journal of comparative neurology, 521 (2013) 3847-3862. [60] T.H. Milhorat, R.M. Kotzen, A.P. Anzil, Stenosis of central canal of spinal cord in man: incidence and pathological findings in 232 autopsy cases, Journal of neurosurgery, 80 (1994) 716-722.

[61] M.A. Stoodley, S.A. Brown, C.J. Brown, N.R. Jones, Arterial pulsation-dependent perivascular cerebrospinal fluid flow into the central canal in the sheep spinal cord, Journal of neurosurgery, 86 (1997) 686-693.

[62] Z. Bi, Chapter 10 - Applications-Fluid Mechanics, in: Z. Bi (Ed.) Finite Element Analysis Applications, Academic Press2018, pp. 379-405.

[63] M. Ghassemi, A. Shahidian, Chapter 4 - Fluid Mechanics, in: M. Ghassemi, A. Shahidian (Eds.) Nano and Bio Heat Transfer and Fluid Flow, Academic Press, Oxford, 2017, pp. 57-87.

[64] B. Vigh, I. Vigh-Teichmann, B. Aros, Special dendritic and axonal endings formed by the cerebrospinal fluid contacting neurons of the spinal cord, Cell and Tissue Research, 183 (1977) 541-552.

[65] B. Vigh, M.J. Manzano e Silva, C.L. Frank, C. Vincze, S.J. Czirok, A. Szabo, A. Lukats, A. Szel, The system of cerebrospinal fluid-contacting neurons. Its supposed role in the nonsynaptic signal transmission of the brain, Histology and histopathology, 19 (2004) 607-628.

[66] X. Lu, X. Geng, L. Zhang, Y. Zeng, H. Dong, H. Yu, Substance P expression in the distal cerebrospinal fluidcontacting neurons and spinal trigeminal nucleus in formalin-induced the orofacial inflammatory pain in rats, Brain research bulletin, 78 (2009) 139-144.

[67] S. Knafo, C. Wyart, Active mechanosensory feedback during locomotion in the zebrafish spinal cord, Current Opinion in Neurobiology, 52 (2018) 48-53.

[68] U.L. Böhm, A. Prendergast, L. Djenoune, S. Nunes Figueiredo, J. Gomez, C. Stokes, S. Kaiser, M. Suster, K. 
Kawakami, M. Charpentier, J.-P. Concordet, J.-P. Rio, F. Del Bene, C. Wyart, CSF-contacting neurons regulate locomotion by relaying mechanical stimuli to spinal circuits, Nature communications, 7 (2016) 10866.

[69] L. Rogenmoser, J. Kernbach, G. Schlaug, C. Gaser, Keeping brains young with making music, Brain Structure and Function, 223 (2018) 297-305.

[70] C. Gaser, G. Schlaug, Brain structures differ between musicians and non-musicians, J Neurosci, 23 (2003) 92409245.

[71] G. SCHLAUG, The Brain of Musicians, Annals of the New York Academy of Sciences, 930 (2001) 281-299.

[72] V. Sluming, J. Brooks, M. Howard, J.J. Downes, N. Roberts, Broca's Area Supports Enhanced Visuospatial Cognition in Orchestral Musicians, The Journal of Neuroscience, 27 (2007) 3799-3806.

[73] T. Rüber, R. Lindenberg, G. Schlaug, Differential adaptation of descending motor tracts in musicians, Cerebral cortex (New York, N.Y. : 1991), 25 (2015) 1490-1498.

[74] K. Schüldt, J. Ekholm, K. Harms-Ringdahl, U.P. Arborelius, G. Németh, Influence of sitting postures on neck and shoulder e.m.g. during arm-hand work movements, Clinical Biomechanics, 2 (1987) 126-139.

[75] J.P. Caneiro, P. O'Sullivan, A. Burnett, A. Barach, D. O'Neil, O. Tveit, K. Olafsdottir, The influence of different sitting postures on head/neck posture and muscle activity, Manual therapy, 15 (2010) 54-60.

[76] S. Levy-Tzedek, H.I. Krebs, J.E. Arle, J.L. Shils, H. Poizner, Rhythmic movement in Parkinson's disease: effects of visual feedback and medication state, Experimental brain research, 211 (2011) 277.

[77] A.L. Taylor Tavares, G.S.X.E. Jefferis, M. Koop, B.C. Hill, T. Hastie, G. Heit, H.M. Bronte-Stewart, Quantitative measurements of alternating finger tapping in Parkinson's disease correlate with UPDRS motor disability and reveal the improvement in fine motor control from medication and deep brain stimulation, Movement Disorders, 20 (2005) 1286-1298.

[78] G. Reifferscheid, H.M. Maes, B. Allner, J. Badurova, S. Belkin, K. Bluhm, F. Brauer, J. Bressling, S. Domeneghetti, T. Elad, S. Fluckiger-Isler, H.J. Grummt, R. Gurtler, A. Hecht, M.B. Heringa, H. Hollert, S. Huber, M. Kramer, A. Magdeburg, H.T. Ratte, R. Sauerborn-Klobucar, A. Sokolowski, P. Soldan, T. Smital, D. Stalter, P. Venier, C. Ziemann, J. Zipperle, S. Buchinger, International round-robin study on the Ames fluctuation test, Environ Mol Mutagen, 53 (2012) 185-197.

[79] T. Markow, N. Ramakrishnan, K. Huang, T. Starner, M. Eicholtz, S. Garrett, H. Profita, A. Scarlata, C. Schooler, A. Tarun, Mobile Music Touch: Vibration stimulus in hand rehabilitation, 2010 4th International Conference on Pervasive Computing Technologies for Healthcare, IEEE, 2010, pp. 1-8.

[80] S. Beveridge, S.A. Herff, B. Buck, G.B. Madden, H.-C. Jabusch, Expertise-related differences in wrist muscle cocontraction in drummers, Frontiers in Psychology, 11 (2020) 1360.

[81] G.T. Uehara, System and method for developing core muscle usage employing music, Google Patents, 2020.

[82] C. Erdem, K.H. Schia, A.R. Jensenius, Vrengt: a shared body-machine instrument for music-dance performance, arXiv preprint arXiv:2010.03779, DOI (2020).

[83] S.K. Wise, Integrating the use of music in movement therapy for patients with spinal cord injuries, American Journal of Dance Therapy, 4 (1981) 42-51.

[84] S. Mark, Case 11: The Case of the Long-Lived Orchestra Conductors, Western Public Health Casebooks, 2016 (2016) 17.

[85] V. Anisimov, G. Zharinov, Lifespan and longevity among representatives of creative professions, Advances in Gerontology, 4 (2014) 83-94.

[86] M. Manturzewska, A biographical study of the life-span development of professional musicians, Psychology of music, 18 (1990) 112-139.

[87] C.Y. Wan, G. Schlaug, Music Making as a Tool for Promoting Brain Plasticity across the Life Span, The Neuroscientist, 16 (2010) 566-577. 
[88] T. Kuusi, J. Haukka, L. Myllykangas, I. Järvelä, Causes of death of professional musicians in the classical genre, Medical problems of performing artists, 34 (2019) 92-97.

[89] A. Cowles, W.W. Beatty, S.J. Nixon, L.J. Lutz, J. Paulk, K. Paulk, E.D. Ross, Musical skill in dementia: a violinist presumed to have Alzheimer's disease learns to play a new song, Neurocase, 9 (2003) 493-503.

[90] L. Fornazzari, T. Castle, S. Nadkarni, M. Ambrose, D. Miranda, N. Apanasiewicz, F. Phillips, Preservation of episodic musical memory in a pianist with Alzheimer disease, Neurology, 66 (2006) 610-611.

[91] S. Parasuraman, Y.S. Purohit, Distress and boredom among orchestra musicians: The two faces of stress, Journal of occupational health psychology, 5 (2000) 74.

[92] W. Brodsky, In the wings of British orchestras: A multi - episode interview study among symphony players, Journal of Occupational and Organizational Psychology, 79 (2006) 673-690.

[93] D.T. Kenny, A. Asher, Life expectancy and cause of death in popular musicians: is the popular musician lifestyle the road to ruin?, Medical problems of performing artists, 31 (2016) 37-44.

[94] C.L. Steckel, Exploration of Flow Among Collegiate Marching Band Participants, Oklahoma State University, 2006. 


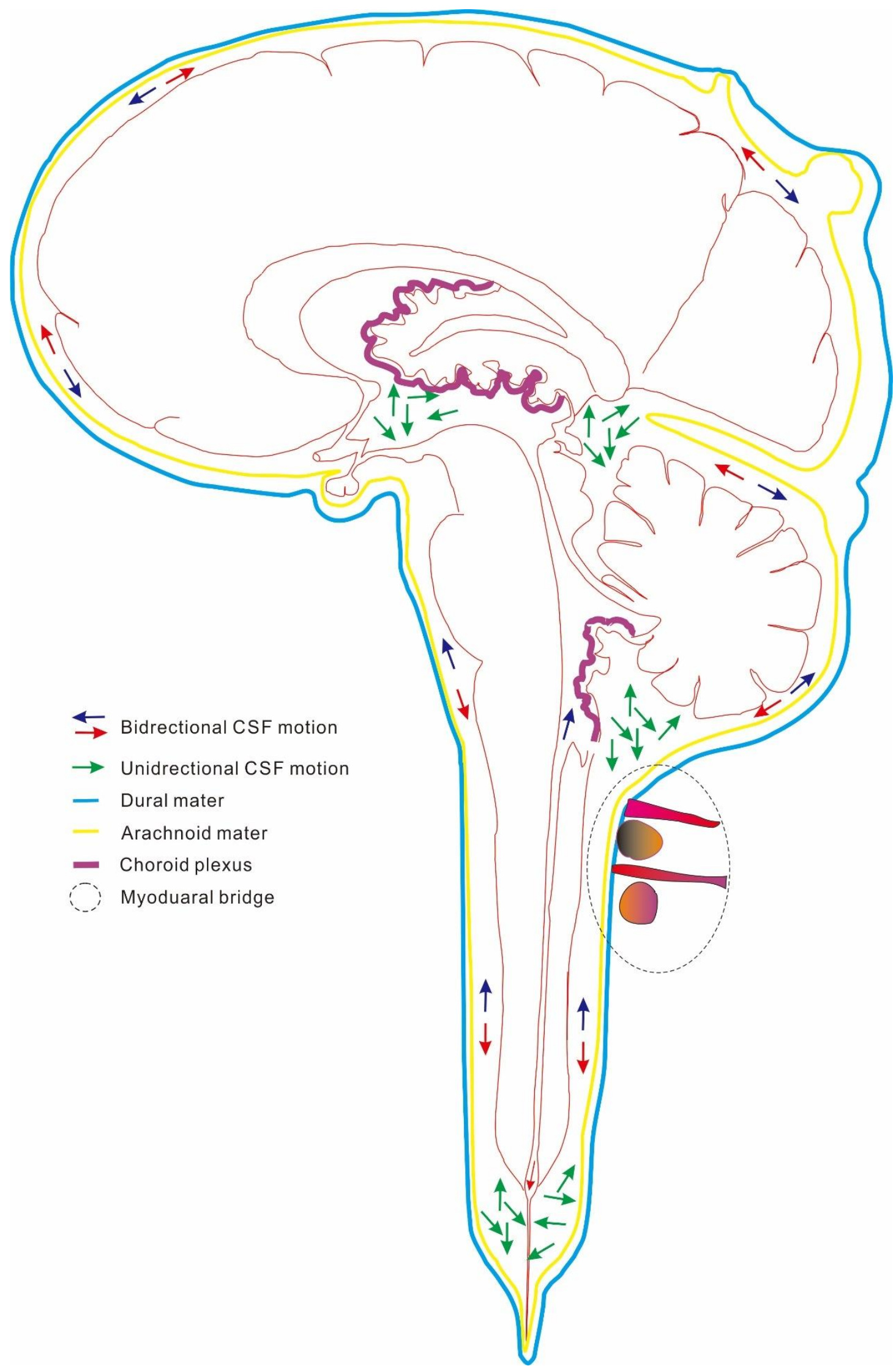

Figure 1 Illustration for theory of CSF motion pattern and different circulation directions. Paired blue and red arrows indicated CSF pulsation motion. Green arrows indicated various directional CSF motion. Choroid plexus indicated purple line is apparatus to produce CSF. 


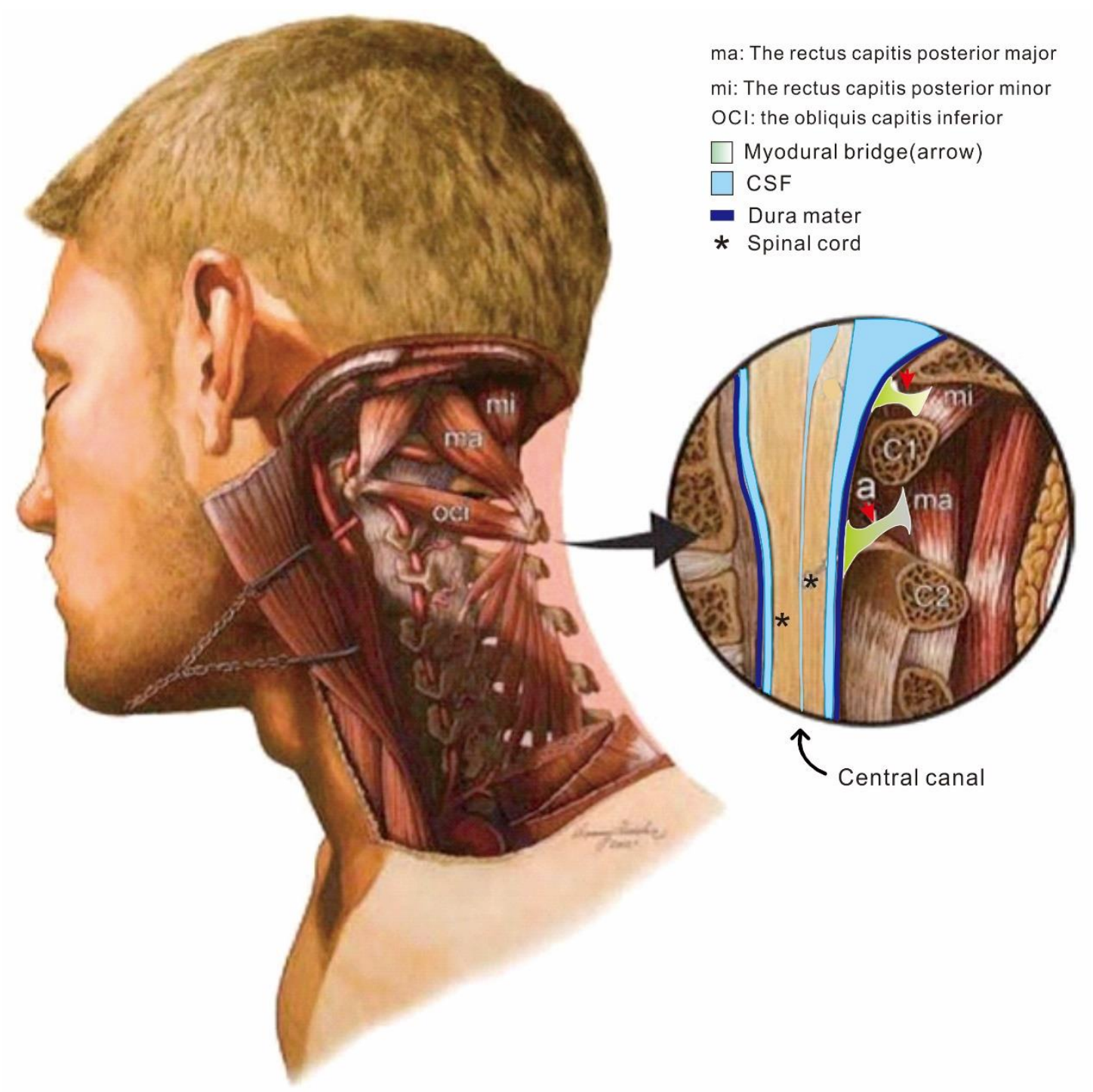

Figure 2 The myodural bridge (MDB) connects muscles to dural mater. We presumed that head, shoulder or upper arm motion could stretch and pull the myodural bridge (MDB), which would act underneath the CSF. Here is relevant anatomy. The cervical myodural bridge (MDB, arrow) directly connected to dural mater (blue line) between $\mathrm{C1}$ and $\mathrm{C2}$.

Acknowledgement: The modified illustration cited with permission from J Can Chiropr Assoc. 2014 Jun;58(2):184-92. (Original anatomical artwork by Frank Scali, D.C., and Danny Quirk. Clin Anat. 2013 May; 26(4):444-9)[9] 


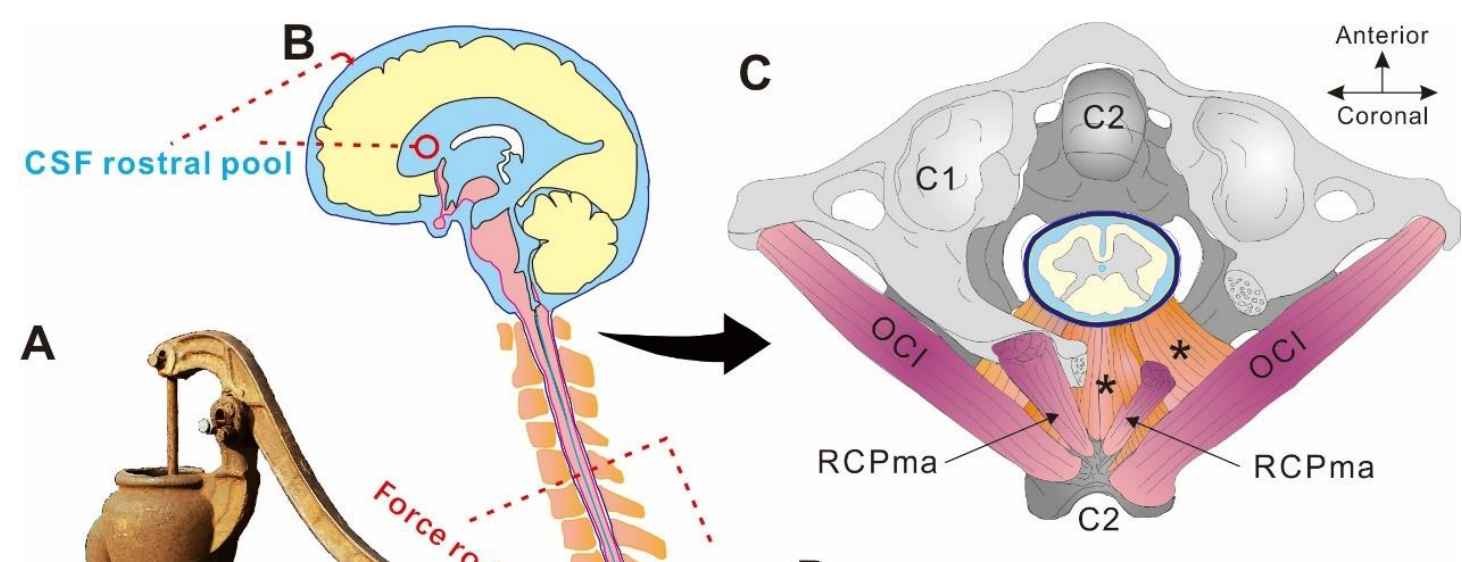

D

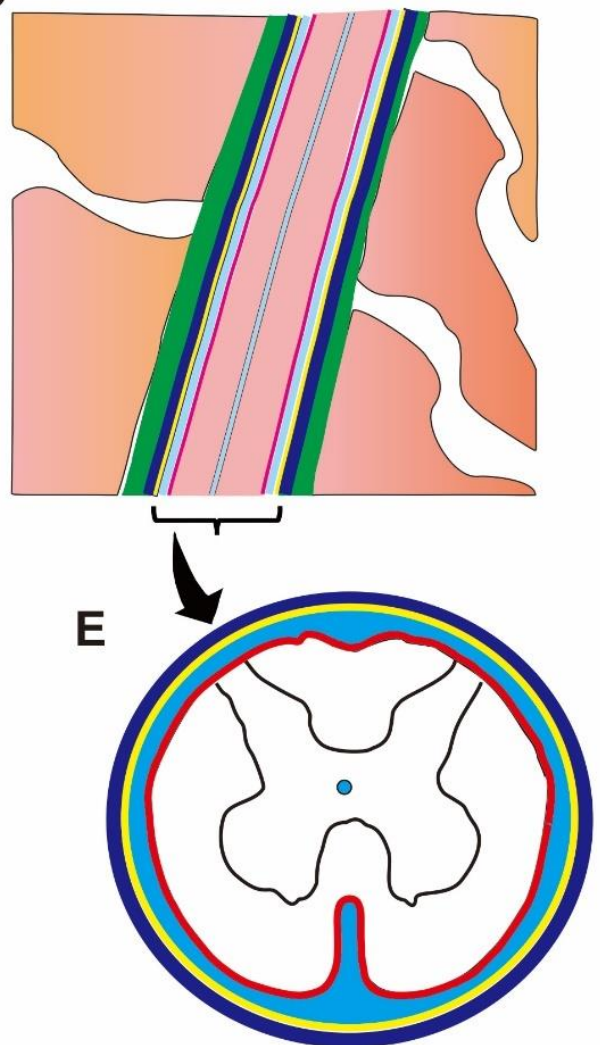

Figure 3 Diagram illustrated mechanical suck or peristaltic pumping for CSF circulation between the SCF rostral pool and caudal pool: a metaphoric parallel between vertebral and lever drum pump. A: An example of lever drum pump, in which force rod is an analogy to spinous process of vertebral column, especially referred to caudal cervical, thoracic and lumber segments. B indicated ventricles, position of myodural bridge and sagittal oriented plane of spinal cord in vertebral column which contained relative static CSF. The CSF rostral pool and CSF caudal pool were illustrated. Rectangle and curved arrows indicated positions for further demonstration in $\mathrm{C}$ and D. $\mathrm{C}$ showed the myodural bridge in coronal plane with $\mathrm{C} 1$ and $\mathrm{C} 2$ vertebrae, obliquus capitis inferior suboccupital muscles (OCI) and rectus capitis posterior majors (RCPma). D: higher magnified illustration from B. E: Diagram of the meninges, CSF and spinal cord showed in transverse section. 


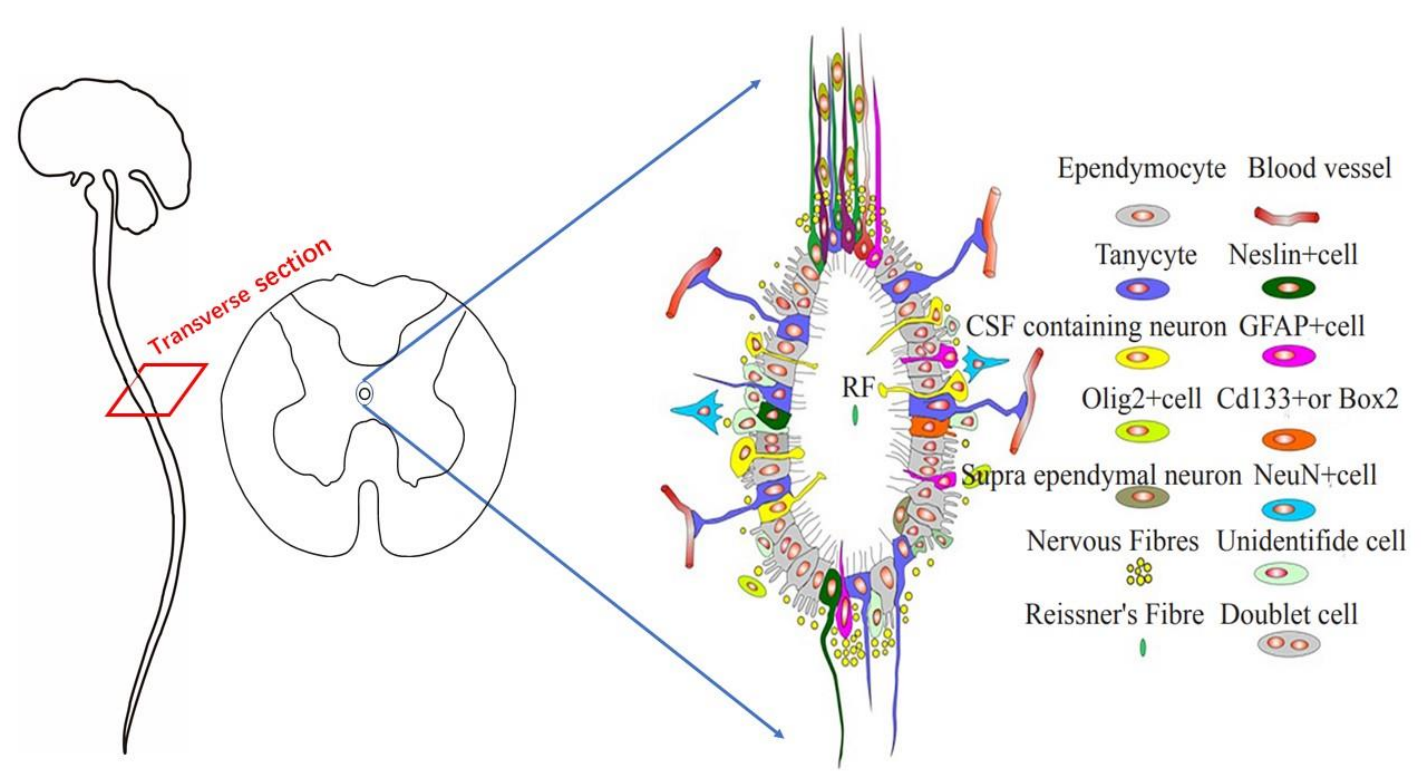

Figure 4. CSF-Ns distributed among ependymal cells or around the $\mathrm{cc}$ in the spinal cord. Both the cc and the CSF circulation maintain a proliferative niche for neural progenitor cells, which play a vital role in development of the brain and spinal cord. Acknowledgement: with permission from our previous article Chin J Neurotrauma Surg (Electronic Edition), 2015, Vol.1, No.3， DOI: 10.3877/cma.j.issn.2095-9141.2015.03.013). Adapted and used with permission original from Hugnot JP, Franzen R. Front Biosci (Landmark Ed), 2011, 16: 1044-1059. Review.
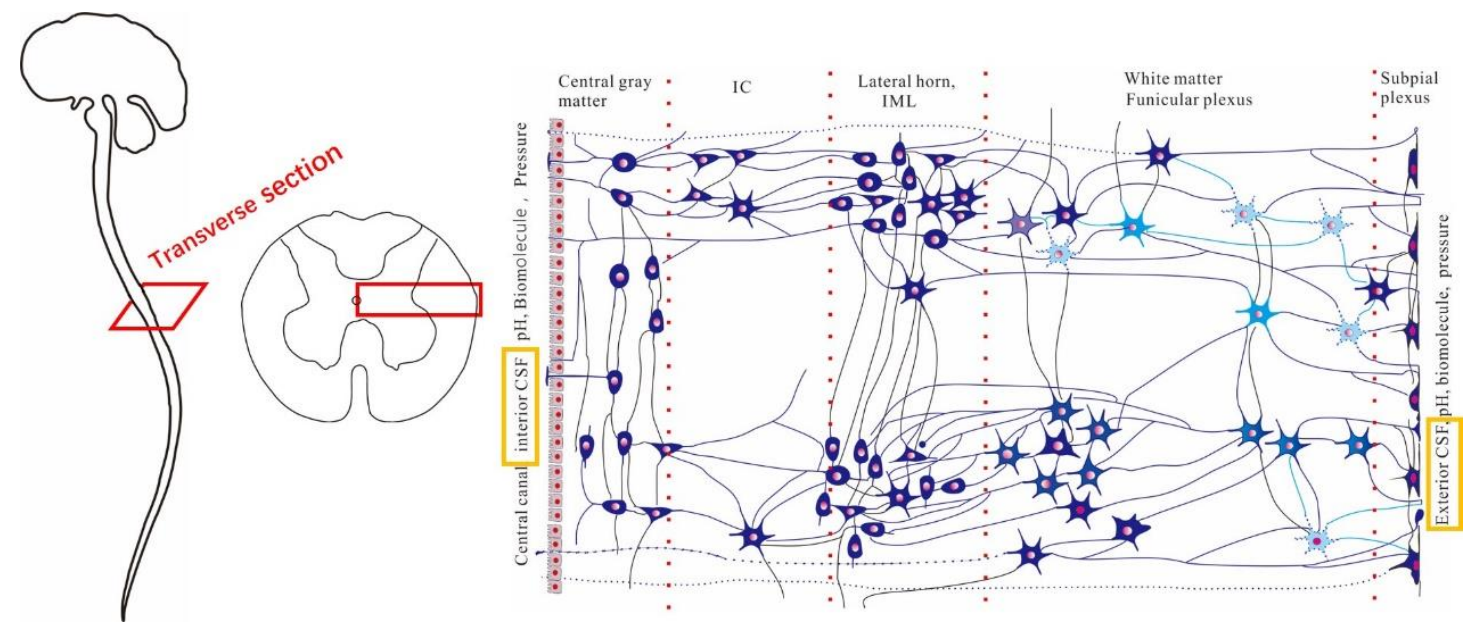

Figure 5. Diagram illustrated the neuronal connectivity in the horizontal arrangement from the central canal to the pial surface in monkey. The subpial plexus and funicular plexus reached the external CSF. The pH, biomolecules and pressure in the CSF may detect by the CSF contacting neuron in the subpial plexus and funicular plexus. IC: intercalated nucleus, IML: intermediolateral N. Adapted and modified from our previous preprint: bioRxiv preprint doi: https://doi.org/10.1101/2020.01.30.927509 


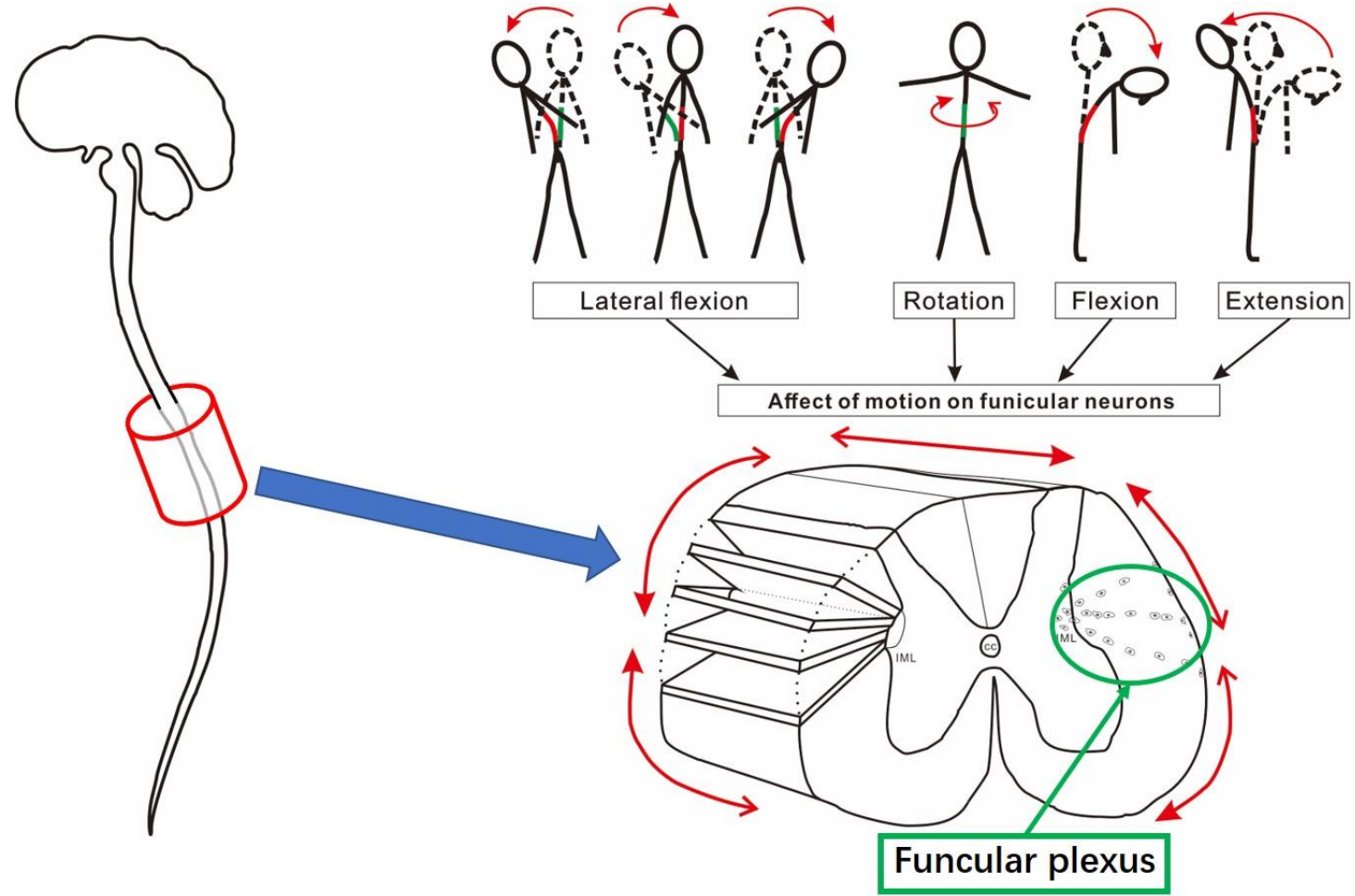

Figure 6. Schematic diagram of mechanosensory modulation featured with funicular plexus in the thoracolumber spinal cord. The supposed sensation device also mention in Figure 4 would detect spinal cord bending or the CSF flows. Body motion Arrows indicated the direction related motion pattern and posture. (Adapted and modified from our previous preprint: bioRxiv preprint doi: https://doi.org/10.1101/2020.01.30.927509) 


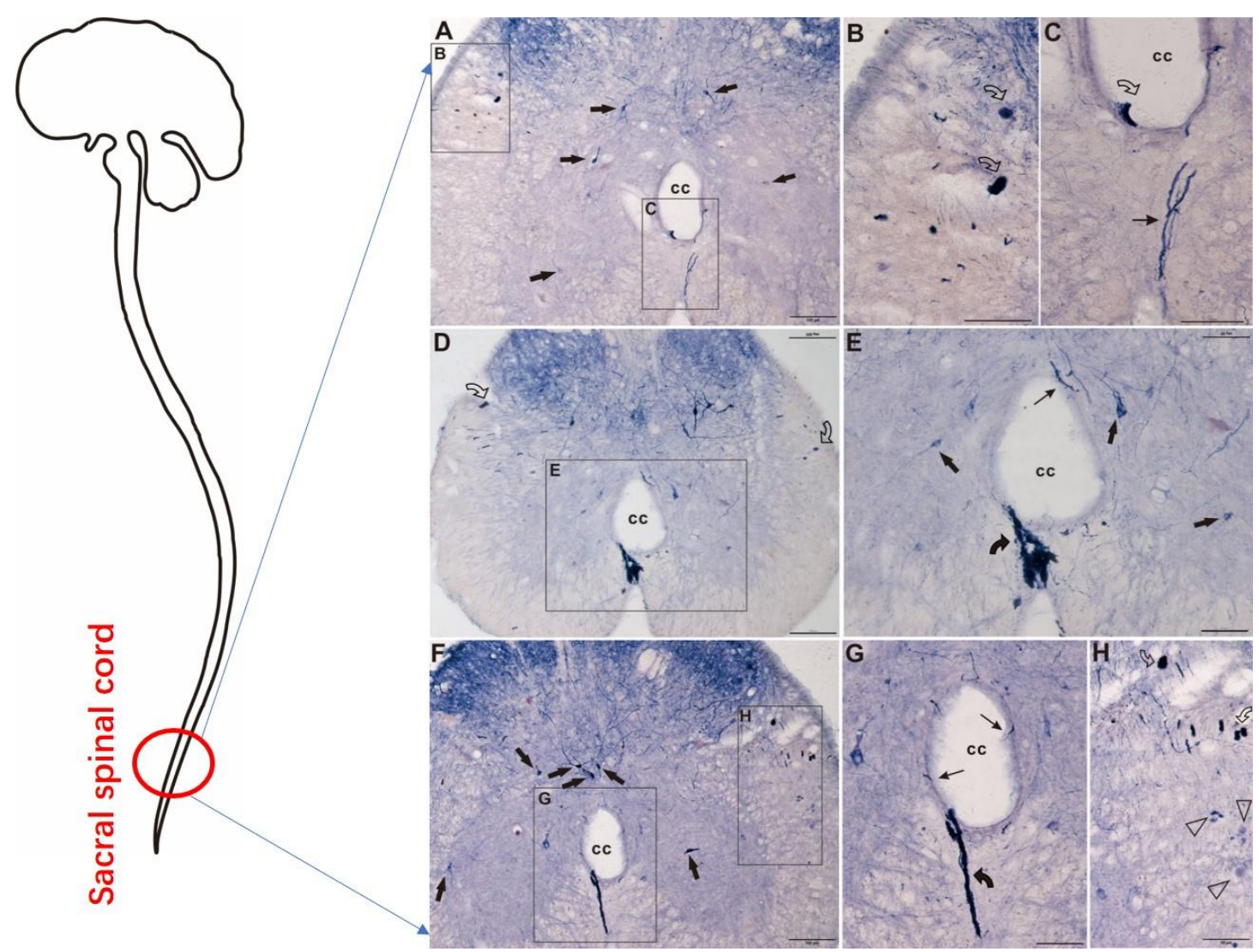

Figure 7. N-d pathway showed between the $\mathrm{cc}$ and the anterior median fissure in aged dog. The swelling dystrophic neurite may be a dysfunctional CSF-N and was supposed to be an aging alteration. A, D and F showed caudal segment of the spinal cord. Arrow indicated neuron. B, C, G and H showed similar pattern for transverse megaloneurites (open curve arrow). $\mathrm{C}$ showed thick neurite (thin arrow). $\mathrm{E}$ and $\mathrm{G}$ showed megaloneurite (curve arrow). Bar in A, D and F $=100 \mu \mathrm{m}$, the other $=50 \mu \mathrm{m}$. (Adapted and modified from our previous preprint: bioRxiv preprint https://doi.org/10.1101/2020.05.02.07445.) 


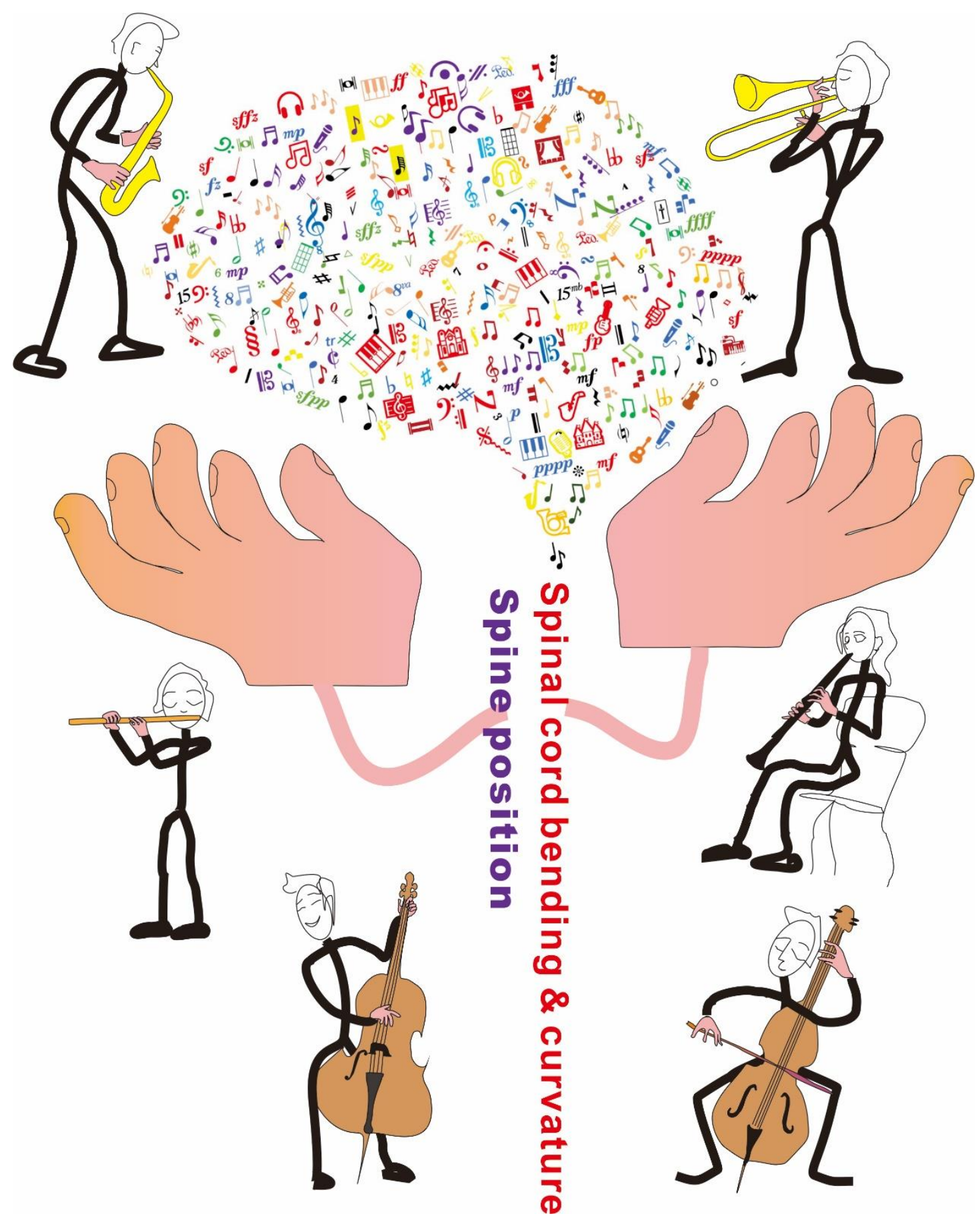

Figure 8 The movement of finger-hand-arm-shoulder-neck-head-spine-leg entity with the brain and spinal cord. 


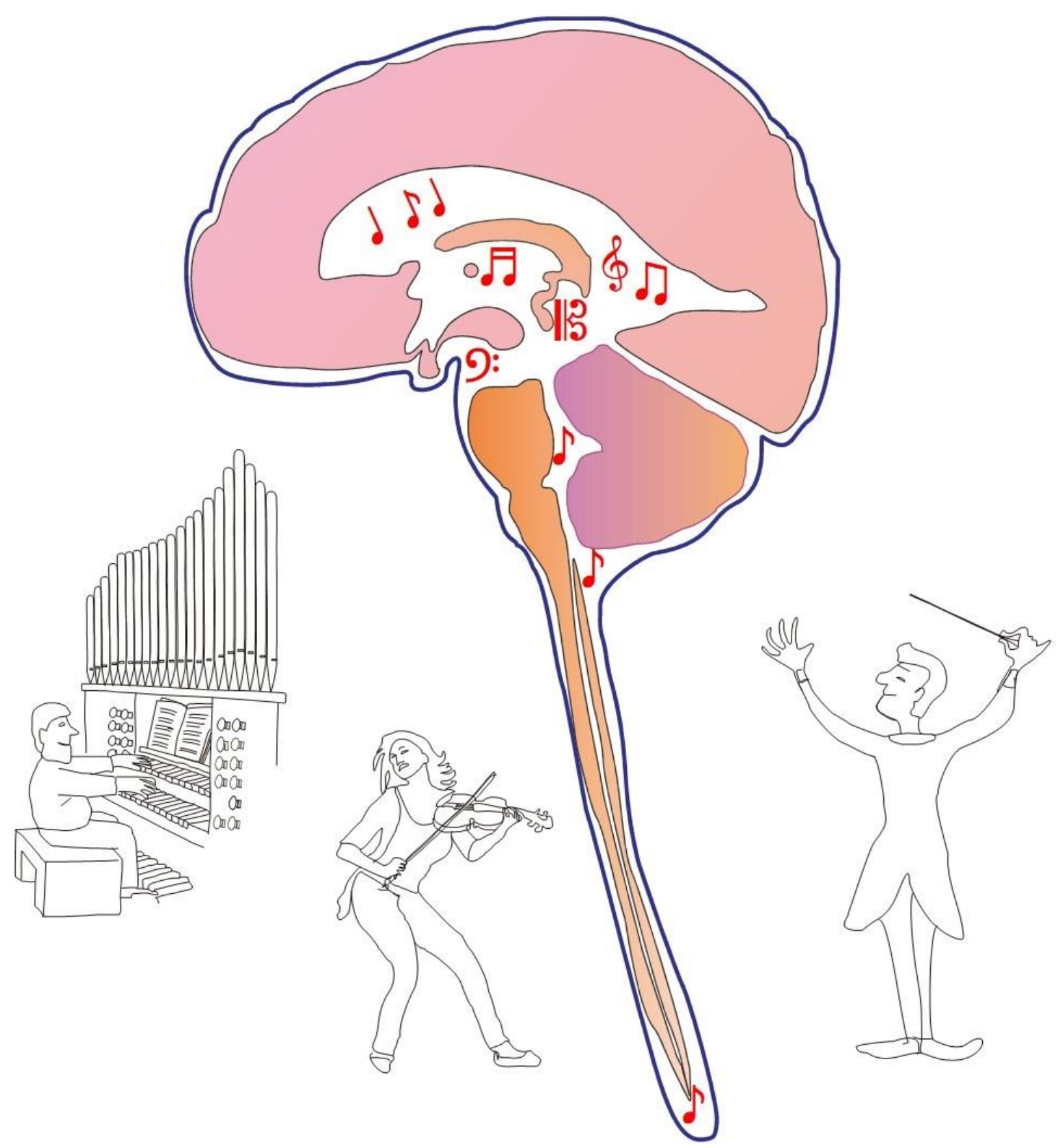

Figure 9. Music and "empathy" in CSF. It is conceptions of music bio-imagination linked to music biomechanics, presented in 16th Annual NeuroMusic Conference "Music in Cross-Cultural Perspective"(2020, Nov 14), originally to demonstrate the idea with music-based intervention. It should be possible used to explain other rhythmic movement effect on CFS motion. 


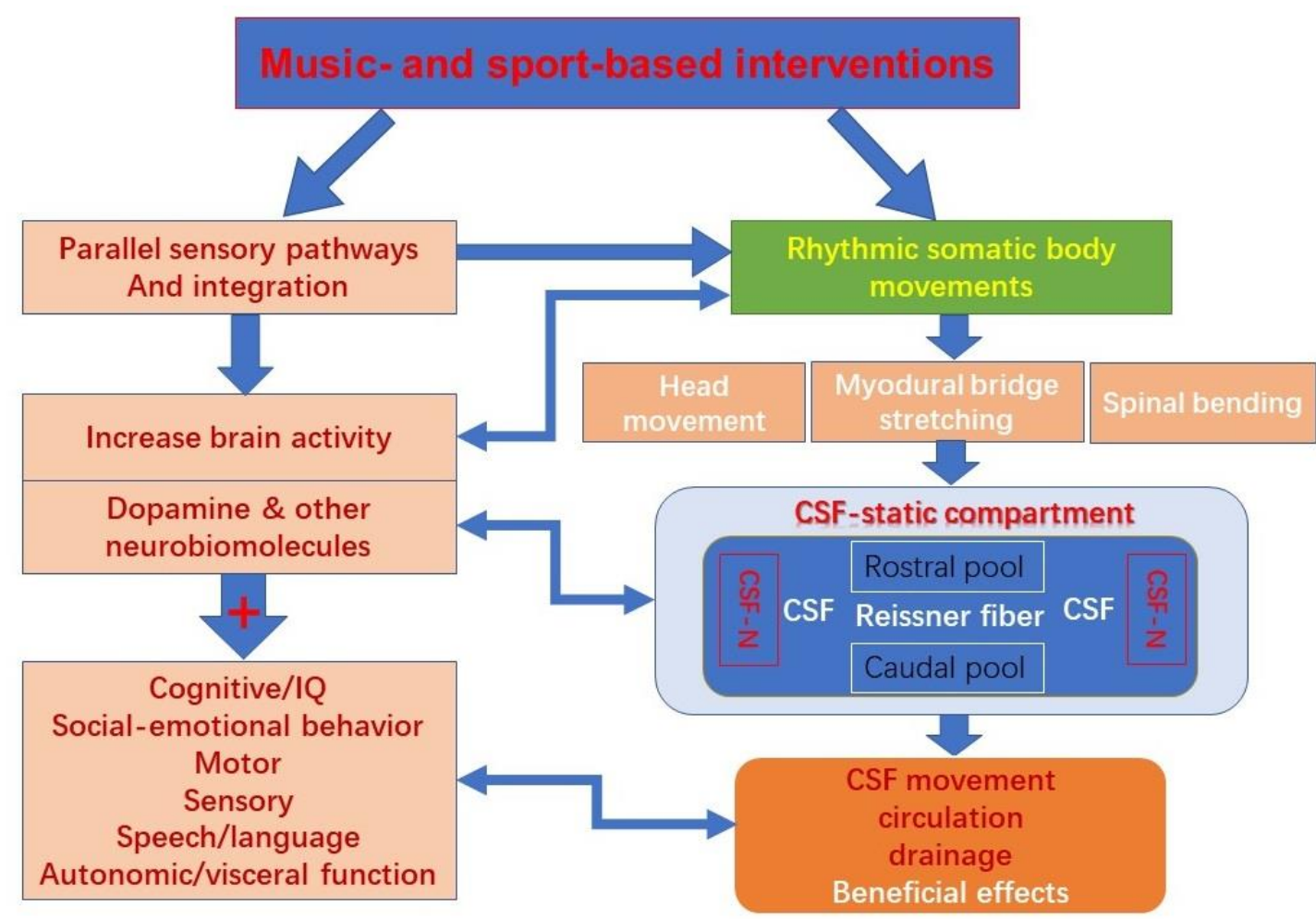

Figure 10 Schematic diagram of the brain basis of rhythmic movement on CSF circulation during music-and sport-based interventions. 